\title{
Environmental analysis of the traffic closure on Piotrowo and Berdychowo streets in Poznań
}

\section{ARTICLE INFO}

Received: 6 September 2021

Revised: 26 September 2021

Accepted: 26 September 202

Available online: 5 October 2021
The article deals with the ecological assessment of the potential road investment, which is the closure of Piotrowo and Berdychowo streets within the campus of the Poznan University of Technology. The research was carried out on a simulation model of the city of Poznan with the use of PTV software. Research has shown that the closure of these streets has virtually no impact on city-wide emissions. However, the emissions deterioration takes place on a local scale, i.e. in the vicinity of the campus of the Poznan University of Technology and on most of the streets leading to it.

Key words: road traffic simulation, environmental analysis, exhaust emissions, road infrastructure

This is an open access article under the CC BY license (http://creativecommons.org/licenses/BY/4.0/)

\section{Introduction}

Transport is one of the main service areas in the world, therefore great emphasis is placed on the process of its development, infrastructure reconstruction, and ensuring the safety and comfort of all road users. For many years, one of the most important aspects of transport has been the assessment of its impact on the natural environment. This assessment is possible through direct measurements of vehicle emissivity, under dynamometer or real conditions. Data on air quality is provided by measurements of concentrations of harmful compounds in the air carried out by, for example, stations of the Provincial Inspectorate for Environmental Protection. In the case of Poznań, both current data and annual reports on air quality in the Poznan agglomeration are available.

The sources of $\mathrm{CO}$ and $\mathrm{HC}$ emissions from means of transport are mainly vehicles with spark-ignition engines. The share of vehicles with spark-ignition and diesel engines in the $\mathrm{NO}_{\mathrm{x}}$ emissions is similar, while the majority of PM emissions are due to vehicles with diesel engines [11]. Particulate matter is one of the most harmful components of engine exhaust [17]. The report of the US Environmental Protection Agency on the harmfulness of exhaust gas from diesel engines [19] showed, on the basis of several dozen independent medical studies of humans and laboratory tests on animals, that PM has carcinogenic properties and contributes in particular to the occurrence of lung cancer. The results of the works $[5,9,13]$ show that the average PM emission decreases when the permitted speed of vehicles on a given section decreases. Among the hydrocarbons present in the exhaust gas, aromatic hydrocarbons, including benzene, are the most toxic [15].

It should be emphasized that the traffic conditions of vehicles, and consequently the operating conditions of their engines, largely determine the level of fuel consumption and the toxicity of exhaust gases [1, 2, 3, 7, 12, 14]. These, in turn, largely depend on the applied infrastructure solutions and road traffic control $[4,8,18]$.

The assessment of the impact of transport on the environment is also possible through simulations. The basic objectives of road traffic modeling often concern environmental issues and include $[10,16]$ :

- construction of a displacement matrix specifying the size of the flows moving between different parts of the analyzed area (e.g. a city),

- construction of traffic maps, determination of the impact of traffic on the environment,

- identifying future transport needs,

- determining the optimal method of reconstructing road network elements,

- determining the optimal stages of the road network expansion or construction stages of a given road investment,

- support in determining the optimal route of new streets and determining their technical parameters,

- support in determining types of road intersections and their parameters along new road routes,

- determination of changes in the traffic distribution on the city's road network after the construction of a new street, intersection, shopping center, entertainment center, sports hall, petrol station, etc.

There are many programs for modeling and simulating traffic on the market, but in Poland the most popular program for modeling and forecasting traffic is VISUM, while the most popular of the traffic simulation program is VISSIM. Both programs were developed by PTV. Currently, these programs are used by municipal units, incl. in Warsaw, Kraków, Wrocław, Poznań, Gdańsk, Kielce, Katowice and Tychy, as well as consulting and design companies [6]. This type of software was also used in the research described in the article.

The object of the research was the analysis of the road section in the city of Poznan, covering the areas next to the academic campus of the Poznan University of Technology.

The thesis is based on a situational analysis of the closure of Piotrowo and Berdychowo Streets (Fig. 1) to public traffic. Currently, these streets are available to every road user, the idea of excluding them from traffic is to close the campus only to people associated with the Poznań Univer- 


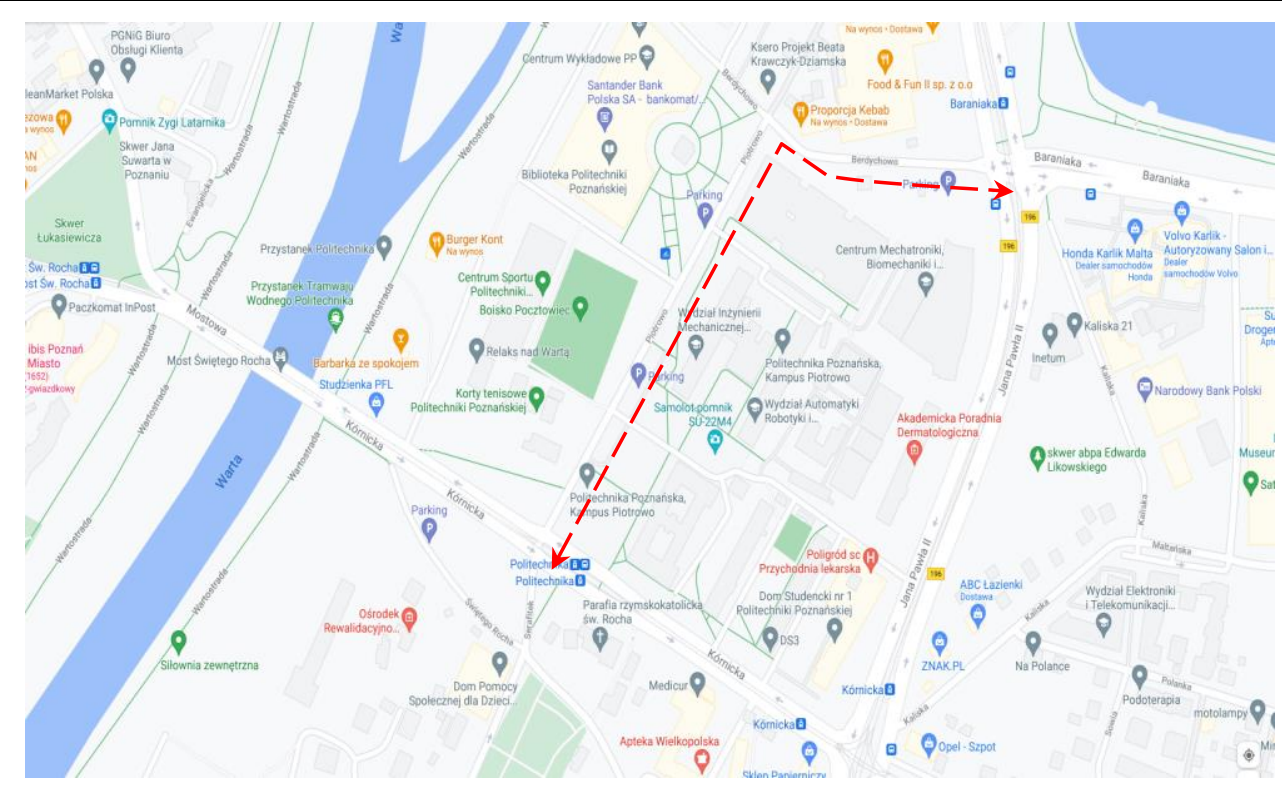

Fig. 1. Piotrowo and Berdychowo Streets in Poznan (red dotted line), the closing of which was analyzed in this article

of Technology, thus increasing the level of security and limiting third parties' access to the area intended for students and university employees. The most likely solution will be the use of barriers with the use of a card reader, the relevant certificates can only be issued to holders of employee cards or students with an electronic ID, which will allow only specific groups to move around the campus. For the sake of comparison, a simulation will be presented for both i.e. the completed initiative and the current state. On the basis of the provided analyzes, conclusions will be presented describing the impact of the investment on the level of emissions of vehicles involved in the traffic.

In order to carry out the analysis, the forecast road model for the city of Poznan was used. The program, equipped with appropriate data on traffic flows after interfering with the road network, simulated the probable loads for the remaining sections in the vicinity of the studied area. On the basis of the obtained results, a comparative analysis was performed for each of the analyzed exhaust gas components for the current state and the state after infrastructural changes. The analysis was divided into three stages due to the level of detail of the description. The first step relates to the infrastructure of the entire city. The second level focuses on a narrowed area covering the closest vicinity of the studied sections. The third stage examines in details selected adjacent road sections (Kórnicka Str., Jana Pawła II Str., Baraniaka Str., Bolesława Krzywoustego Str. and the bridge of St. Roch).

\section{Results of simulation tests and their analysis}

The first stage of analysis - the infrastructure of the entire city

Figures 2 and 3 show, respectively, the results of traffic simulations for the current state and after the investment in the afternoon peak conditions. Assuming the general analysis, i.e. the impact of excluding Piotrowo and Berdychowo streets for all road traffic in the city of Poznan, it can be seen that there is practically no impact on the global emission of individual exhaust gas components (Fig. 4).
Second stage of analysis - adjacent infrastructure

The next stage is based on the analysis of the infrastructure area directly adjacent to the Poznań University of Technology and streets closed to vehicle traffic. As shown in Figure 5, the exclusion of the analyzed streets causes an increase in the emission of exhaust components from vehicles participating in the traffic in this area, in particular, an increase in $\mathrm{CO}$ emissions can be seen.

The third stage of analysis - emissions on individual streets

In the last stage, a detailed analysis is presented, i.e. the emissions values for individual streets adjacent to the change area. The following sections and streets were taken into account:

1. Jana Pawła II Street (from Rondo Śródka do Rondo Rataje),

2. Kórnicka Street,

3. St. Roch bridge,

4. Baraniaka Street,

5. Bolesława Krzywoustego Street.

Diverse changes in emissions were obtained on individual analyzed sections (Figures 6-10). For Jana Pawła II Street (Fig. 6) a slight relative increase in emissions was obtained, mainly in terms of CO. However, it is a very busy street, hence the high absolute values of emissions. The traffic on Jana Pawła II Street is only slightly supplied by Piotrowo Street. Large - by about $50 \%$ - increases in emissions were recorded at Kórnicka Street (Fig. 7). This is due to the fact that this street mainly takes over the traffic that would normally take place along Piotrowo Street. Emission on the St. Roch bridge after the closure of ul. Piotrowo is slightly smaller (Fig. 8). This may be associated with the resignation of some travelers from traveling on this bridge and choosing alternative travel routes. We can observe a similar situation for Bolesława Krzywoustego Street (Fig. 9). Piotrowo Street is largely supplied by vehicles running along Baraniaka Str., similarly in the opposite direction, many vehicles from Piotrowo Str. drive through the intersection straight ahead, continuing along Baraniaka Str. Hence the closure of Piotrowo Street generates a significant reduction in emissions at Baraniaka Str. (Fig. 10). 


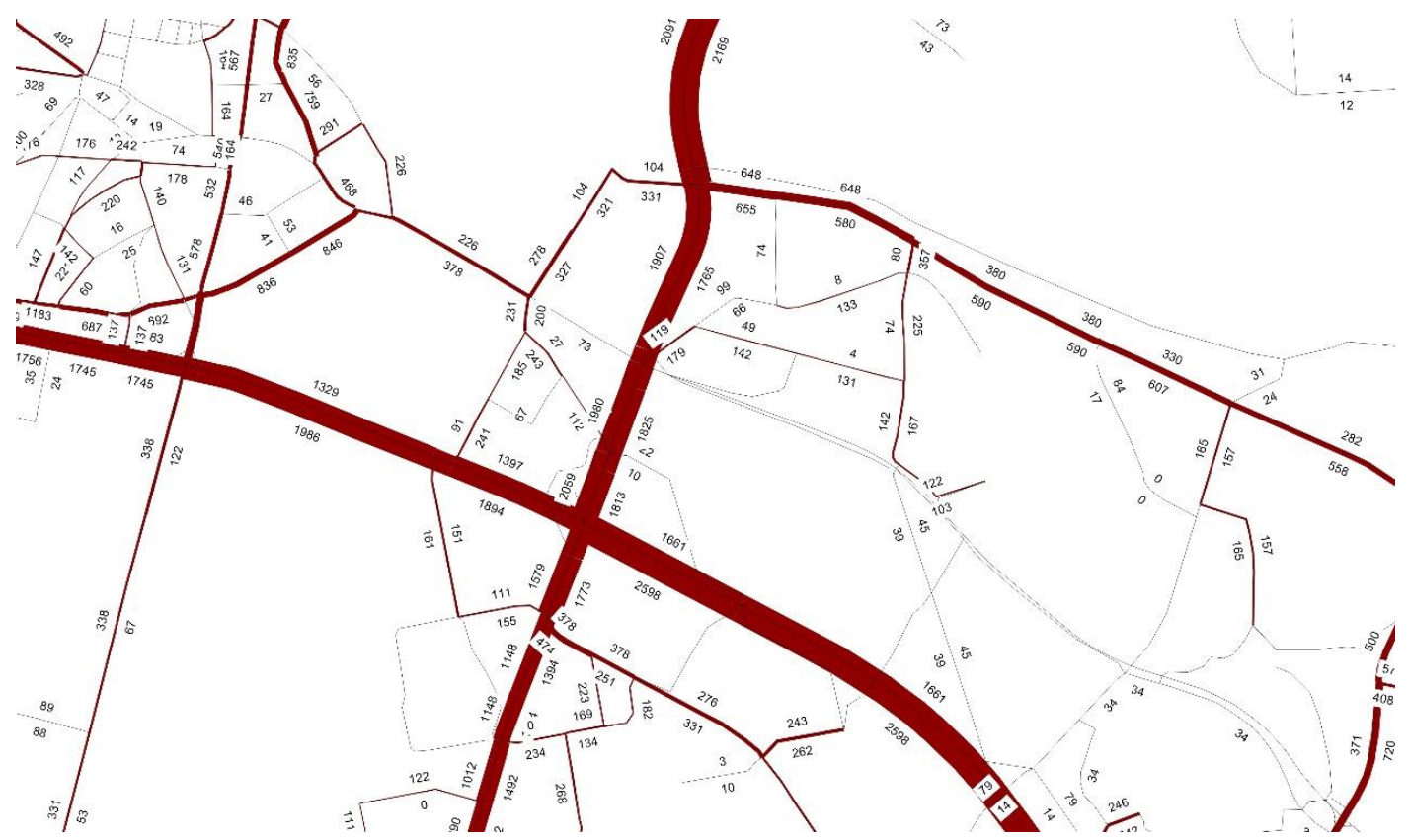

Fig. 2. Distribution of vehicle traffic in the analyzed area as it is in the afternoon peak

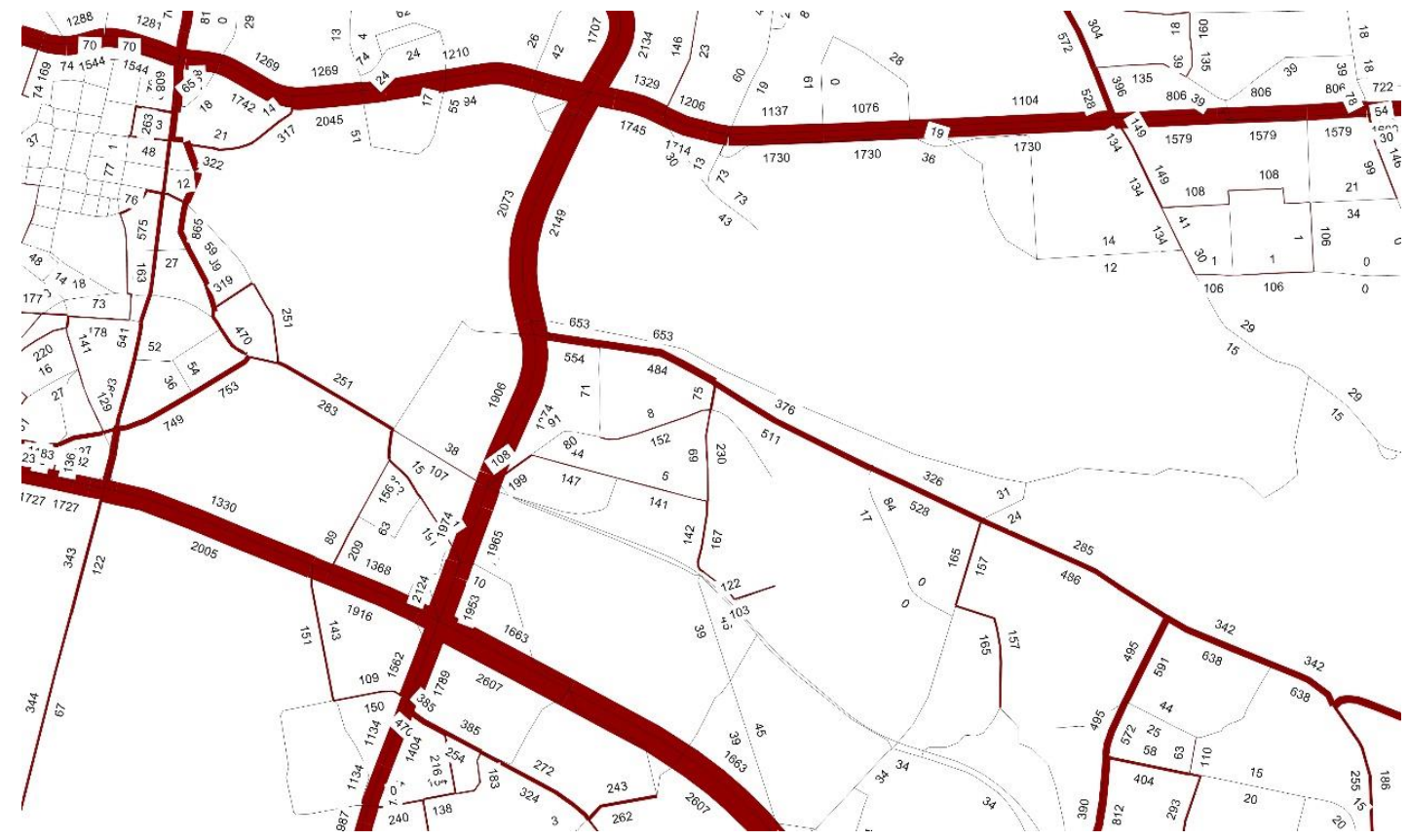

Fig. 3. Traffic distribution in the analyzed area in the afternoon rush hours after the closure of Piotrowo and Berdychowo streets

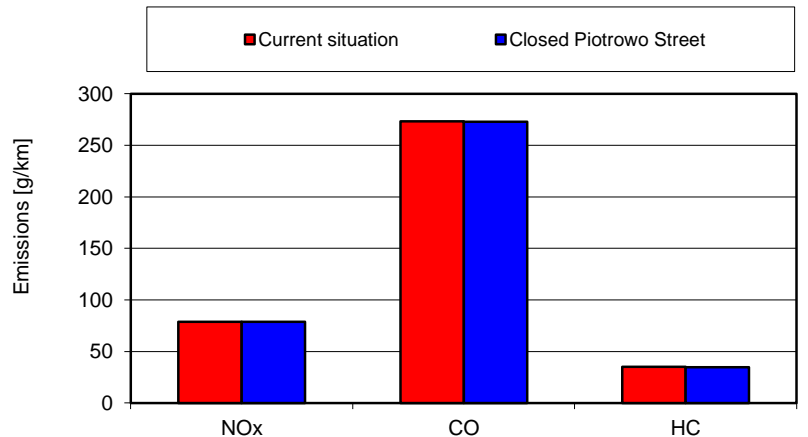

Fig. 4. Average vehicle emissions on the streets of Poznań in the afternoon rush hours

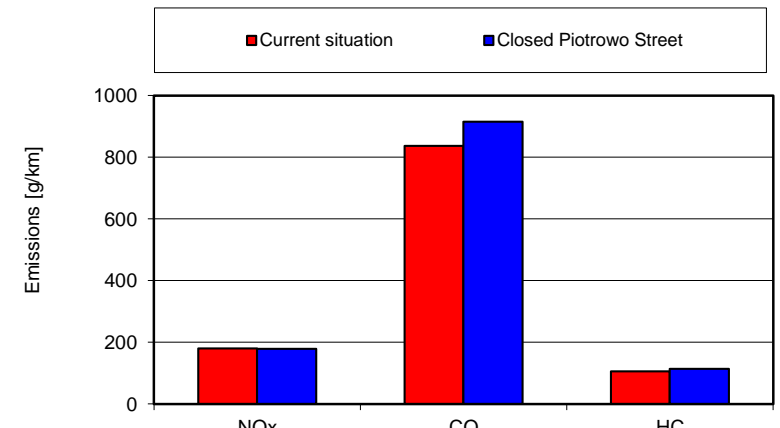

NOx

$\mathrm{HC}$

Fig. 5. Average vehicle emissions in the area directly adjacent to the Poznań University of Technology at Piotrowo Street in the afternoon rush 


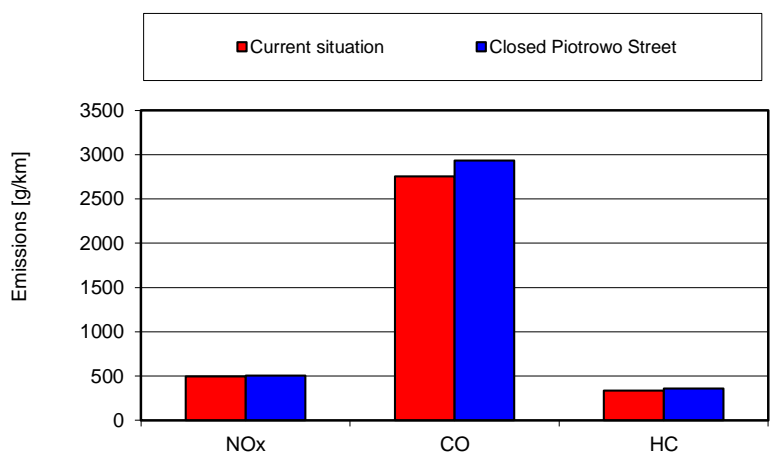

Fig. 6. Emissions of vehicles in the afternoon peak at Jana Pawła II Str.

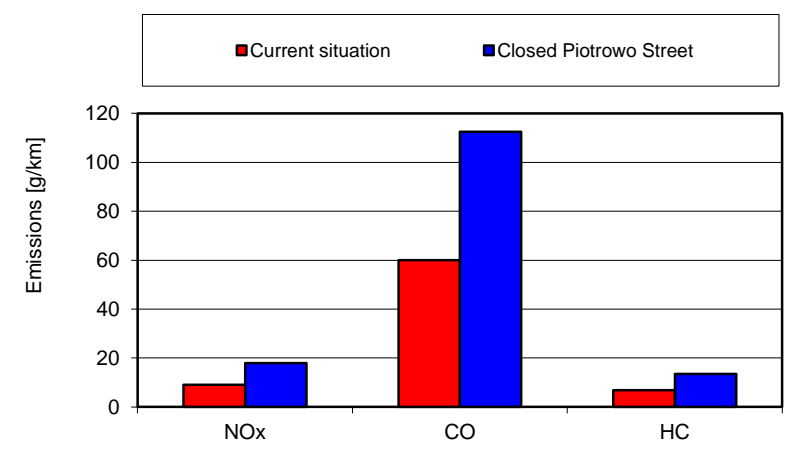

Fig. 7. Emissions of vehicles in the afternoon peak at Kórnicka Str.

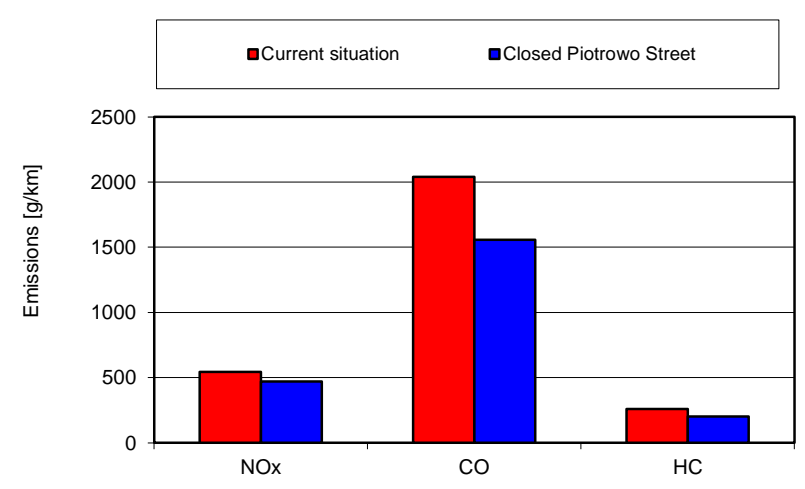

Fig. 10. Emissions of vehicles in the afternoon peak at Baraniaka Str.

\section{Conclusions}

Modeling and simulation programs are a useful tool in the environmental assessment of road investments. The accuracy of the results is influenced by many factors, starting with the selection of the simulator, the existing additional library that calculates ecological aspects, ending with

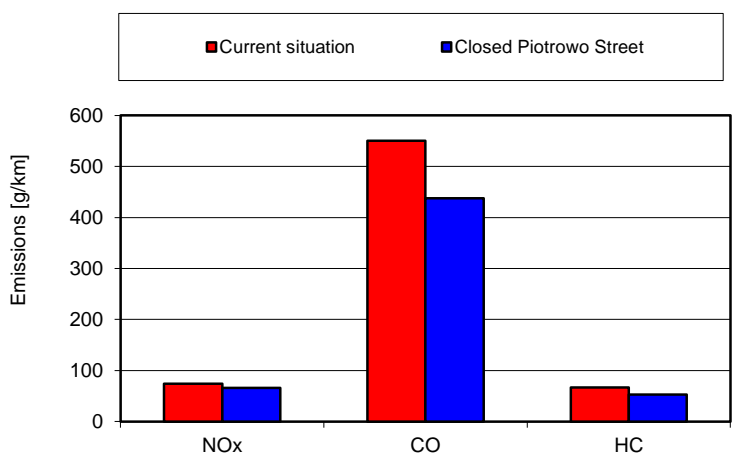

Fig. 8. Emissions of vehicles in the afternoon peak on the St. Roch bridge

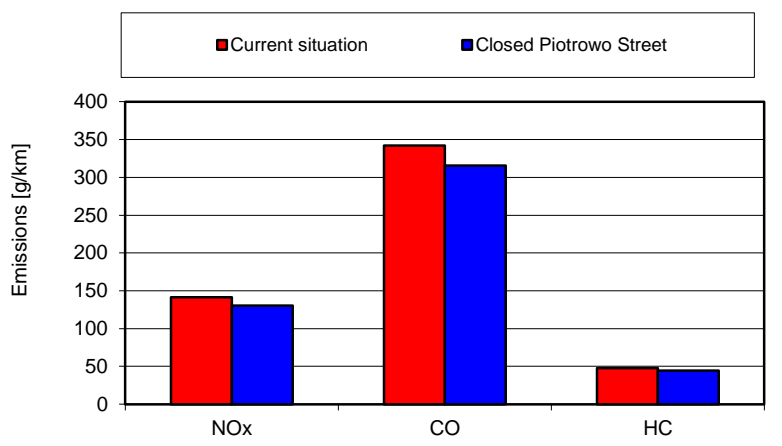

Fig. 9. Emissions of vehicles in the afternoon peak at Bolesława Krzywoustego Str.

the volume of collected data. The forecasted model, as the name suggests, presents only approximate values and should not be treated as a real model.

Based on the conducted research, it can be concluded that the closure of Piotrowo and Berdychowo Streets in Poznań to public traffic does not have a significant impact on the environmental situation in the entire city in terms of the exhaust emissions. On this scale, the closure of these streets generates changes in emissions at the level of at most per-milles. However, the closure of Piotrowo and Berdychowo streets has a more significant negative impact on a local scale. When analyzing the areas adjacent to the campus of the Poznań University of Technology, an increase in the exhaust emissions by several percent is observed. On some streets (Kórnicka Str.) emission increase reaches $50 \%$. On others, however, emissions are declining. Ultimately, an unambiguous environmental assessment of this solution is difficult. It can be assumed to be neutral or slightly negative.

\section{Bibliography}

[1] BEBKIEWICZ, K., CHŁOPEK, Z., SZCZEPAŃSKI, K. et al. The influence of the properties of vehicles traffic on the total pollutant emission. Zeszyty Naukowe Instytutu Pojazdów Politechniki Warszawskiej. 2017, 1.

[2] BIELACZYC, P., MERKISZ, J., PIELECHA, J. Stan cieplny silnika spalinowego a emisja związków szkodliwych. Wydawnictwo Politechniki Poznańskiej, Poznań 2001.

[3] CHŁOPEK, Z., LASOCKI, J. Correlation investigations into pollutant emission and the operational states of compression-ignition engines in dynamic tests. Combustion Engines. 2017, 169(2), 87-92. https://doi.org/10.19206/CE-2017-215

[4] CORRIERE, F., GUERRIERI, M., TICALI, D. et al. Estimation of air pollutant emissions in flower roundabouts and in conventional roundabouts. Archives of Civil Engineering. 2013, 2, 229-246. https://doi.org/10.2478/ace-2013-0012 
